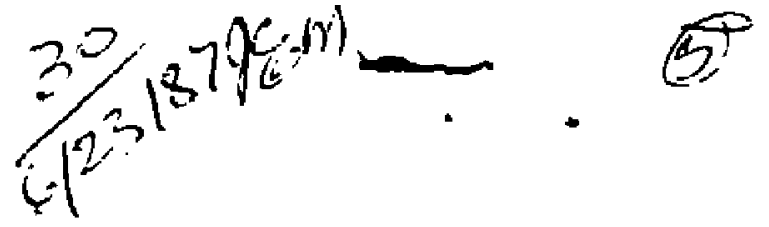

\title{
DE87 010844
}

The Mark III Vertex Chamber: Studies Using DME*

\author{
Dale Pitman \\ Representing the Mark III Collaboration ${ }^{\dagger}$ \\ Stonford Linear Accelerator Center, Stonford, CA O4505
}

\begin{abstract}
We have performed studies using a prototype of a pressurised wire vertex chamber with $8 \mathrm{~mm}$ diametes straw geometry. We obtain $35 \mu \mathrm{m}$ opztisl resclution using dimethyl ether (DME) \& 1 bar and $30 \mu \mathrm{m}$ using argon ethane (50/50 mixture) at 4 bar. Preliminary studies show the DME to adversely affect such materials as aluminised Mylar and Delrin.
\end{abstract}

- Worl aupported by the Departinent of Energy, under contrats, DE-AC03-76SFCosis.

1 The MaRkIII Verex Chamber Group in: J. Adler, T. Boiton, K. Bunaell, E. Cheu, T. Frene, C. Grab, G. Marnheri, R. Mir, A. Odien, D. Pilmen, W. Stockhuure, W. Tohi, F. Vila, S. Wuserblesb and B. W'uniewaki.

Talk presented at the International Conference on Advances in Experimental Methods for Colliding Beam Physics

Stanford Linear Accelerator, Stanford, CA 94305

March 913, 1987 
position the strews have been placed to an accuracy of $\pm 50 \mu \mathrm{m}$ for the axial layers and $\pm 125 \mathrm{pm}$ for the stereo layers.

The aluminised Mylas straws are $\mathrm{mm}$ in diameter and the walls ase raughly $100 \mu \mathrm{m}$ thick. The straw is constructed from sheets of $25 \mu \mathrm{m}$ and $50 \mu \mathrm{m}$ thick Mylar coated electrolytically on one side with $0.25-0.30 \mu m$ aluminum. The sheets are cut into nartow strips, wound in a barber-shop pole fashion and laminated together, so that the aluminum forms the inner and outer surfaces. $A$ Delrin ${ }^{1}$ feedthrough is held in place at each end of the atraw by an aluminum collar, glued to the straw using a silver-loaded epoxy. The epoxy also electrically connects the inner and outer aluminum surfaces of the straws.

The straws are lessioned at 500 grams by preparing the straws 0.6 mo shorter than the distance between the two endplates and stretching them during instal. lation until they touch the endplates. The straw ground is thus electrically connected to the endplate and beam pipe assembly. The feedthrough passes anugly through the endplate hole and is secured on the back side with an aluminum nut.

The chamber cente wires are $50 \mu \mathrm{m}$ diameter gold-plated tungsten tensioned at 275 g. The oense wires are held in place by crimping stainless steel pins which have been press-fitled into the Delrin feedthroughs. The stainless steel pins have an ovter diameter of $1 \mathrm{~mm}$ and an inner diameter of $115 \mu \mathrm{m}$. Signals from one end of the sense wire are read out along the same coaxial cable as supplies the high voltage. The cables, which connect directly to the back of the inner endplates, pass through the outer endpla tes whate a $1 \mathrm{~cm}$ thick layer of

1 Delria in a regintered tradem ark of E. I. Du Pont de Nemoun L Co. (Le.). We heve used Delrio 500. 
Stycast 2850 FT/24 LV epoxy provides a piessuretight aeal. The pins at the other end of the sense wires are covered with Delrin and shielded with $5 \mathrm{~cm}$ long brass collars. The use of the brass shields along with the uninterrupted couxial readout cables reduces the crosstalk considerably.

\section{Prototype Test:}

A prototype of the verlex chamber was uaed to atudy various gases and gas pressures, sense wire dismeters, and operating conditionn. The construetion of the straws in the prototype was identical to that ured in the vertex chamber. The geometrical arrangement of the straws in the prototype was different. Cosmic ray data from two sels of triplets staggered by approximately $\pm 100 \mu$ mere used to calculate the resolution by fiting a Gaussian to the distribution,

$$
0=\left(d\left(t_{1}\right)+d\left(t_{3}\right)\right) / 2-d\left(t_{2}\right),
$$

where $t_{1}$ is the drift time for straw $i_{\text {, and }} d\left(l_{1}\right)$ is the drift distance corresponding to the time $t_{i}$. For saturaled gases such as argon/ethane, $d(t)=$ vpt, where $v_{D}$, the drift velocity, remoins relatively constant $(50 \mu \mathrm{m} / \mathrm{ms})$ at high voltuges. For DME, in which the drift velocity varies with the drift distance, we have determined $d(t)$ using a parametrization derived from a formula of Bari at al. (CERN EP/86-56).

Figure 2 shows the single tube resolution, $\sigma_{\text {twdr }}$, obtained using the prototype asscmbly. Assuming the three tubes in a triplet contribute equally to the resolution, $\sigma_{\text {tubs }}=\sqrt{2 / 3} \sigma$. The data includes tracks at all radial and longitudinal 
positions. No corrections bave been applied $a s$ function of the longitudinal position of the trark. We obtain $35 \mu \mathrm{m}$ spatial resolution at 1 bar using DME and $30 \mu \mathrm{m}$ resolution for argon/ethane at $4 \mathrm{bar}$. The optimum resolution obtained using DME semains fuirly constent over a broad sange of operating voltages, in contrast with that obtained using argon/etinene which is quite sensitive to the vohage.

\section{Materiale Studies}

A study was undertakes to evaluste the potential effects on the atraws of pressurised air, DME, argon/ethane (50/50 mixture) and argon/elhane (50/50) with a small (0.2\%) percentage of water. One metre long samples of the strawt, half with feedthroughs and half without, and $20 \mathrm{~cm} \times 3 \mathrm{~m} \times 25 \mu \mathrm{m}$ sheets of aluminised Mylat were plated in pressurised containers. Con(rol sapoples were left exposed to the ambient temperature and piessure in our clean room.

The straws weighed between 3 and 6 g. depending upon whether they contained Delriu feedthroughs, and the aluminised Mylar sheets weighed about $18 \mathrm{~g}$. The eccuracy of the measurement was 0.01 E. The lengths of the Mylas and of those straws containing feedthroughs werc measured to an accuracy of $1.25 \mathrm{~mm}$.

The samples were removed from the containers after one month and were measured. The results are shown in Figure 3 . The relative weights of the camples exposed to DME increased by approximately $10^{-2}$ and the relative lengths increased by about $10^{-3}$. No significant change was observed for the samples in other eases. It was also noticed that the Delrin feedihroughs exposed to DME swelled and the sheets exposed to DME exhibited a strong tendency to 
curl along their lengths.

\section{Conctucion:}

Good spatial resolution from a prototype wire vertex chambet has been obtained at 1 bar using DME and at i bay using argon/ethane (50/50). Preliminary results, however, show that DME adversely affects at least two common drift chamber materials, Mylar and Delrin. Further studies must be performed to ucertain the extent of the effects on these and other drift ehomber materials. The effects of DME on Kapton;" Stesalit and G-10 are currently being investigated.

\section{Acknowledgement:}

1 would like to thank E. Clewis fot her help in the preparntion of this papez and L. Salgado and $\mathbf{W}$. Wadley for their help in the building of the chamber.

\section{Figure Captions}

Figure 1. A cross rection of the vertex chamber at the interaction point. The inner four and last four layers have straws parallel to the axis of the beam pipe. The middie four layers have straws at small angles relative to the beam pipe axis. The 6rot layer is at a radjal distance of $5.4 \mathrm{~cm}$ and the last layer is at $13.0 \mathrm{~cm}$.

Figure 2. The single tube resolution obtained using a prototype for a) argon/ethane (50/50) at various pressures as a function of the voltage on the senee wire, and b) DME at 1 bar as a function of the voltage.

\footnotetext{
- Kapton in * registered urademart of E. 1. Du Pant de Nemoura 4 Co. (tac.)
} 
Figure S. Measurements made of the changes in length and weight of samples of aluminised Mylar straws and sheets after exposute to variuus gaves. Samples were exposed to pressurised air, DME, argon/ethane (50/50), and argon/ethane with $0.2 \%$ water. There was also a control sample. a) Changes in the relative weight $(\Delta W / W)$. b) Changes in the relative length $(\Delta L / L)$.

\section{DISCLAIMER}

This report was prepared as an account of work sponsored by ar agency of the United States Govirnment. Neither the United States Government nos any agency thereof, nor any of theit employeer, makes any warranty, express or implied, or assumes any legal liability or responsibility for the accuracy. completeness, or usefulness of any information, apparatus, product, or process disclesed, or represents that its use would not infringe privately uwned rights. Refer. ence herein to any specific commescial product, process, of service by trade name, Irademark, manufacturer, or otherwise does not necessarily constitute or imply its endorsement, recommendation, of favoring by the United States Government or any agency thercol. The views and opinions of authors expressed herein do not necessarily state or reflect those of the United States Government or any agency thereor. 


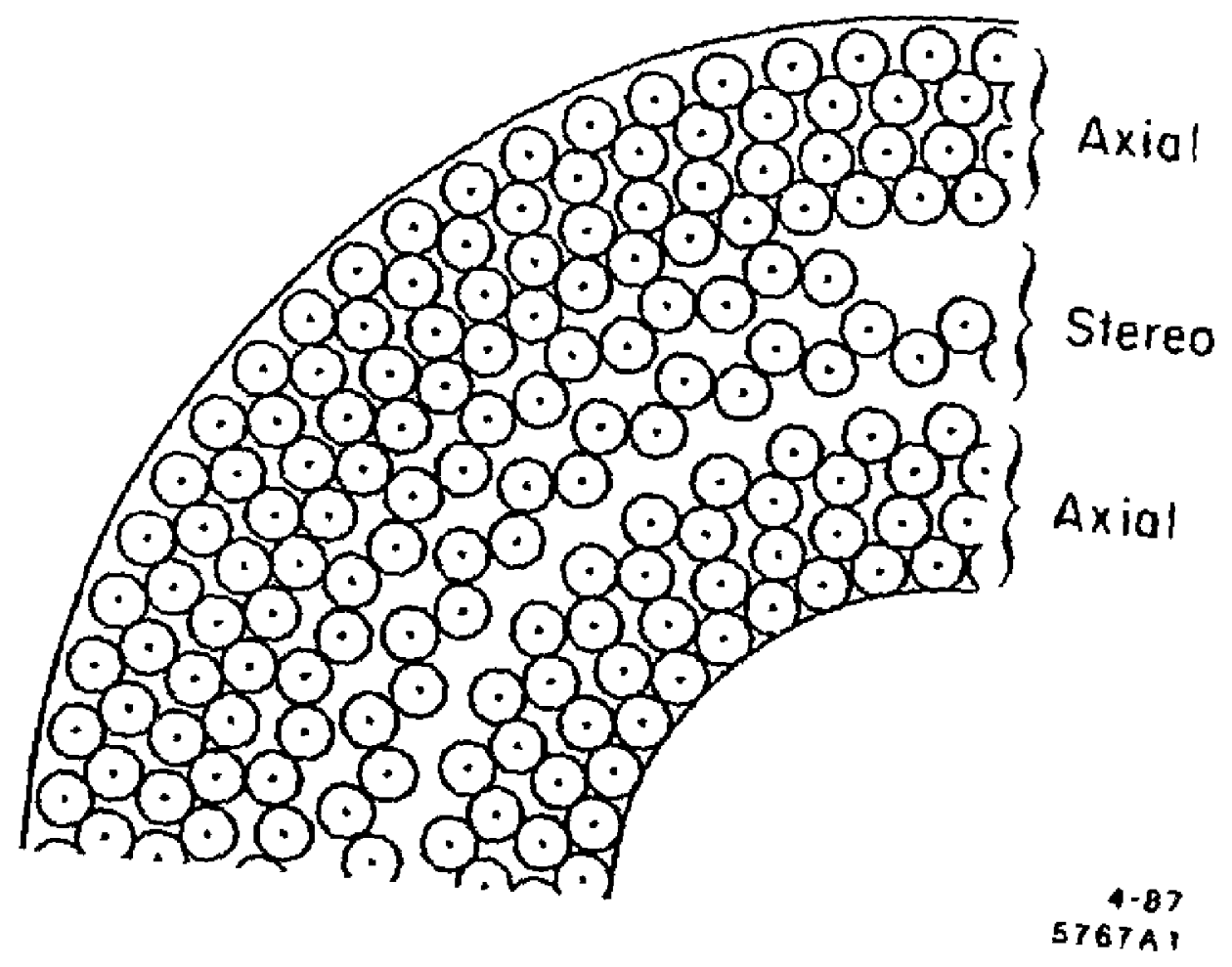

Fig. 1 


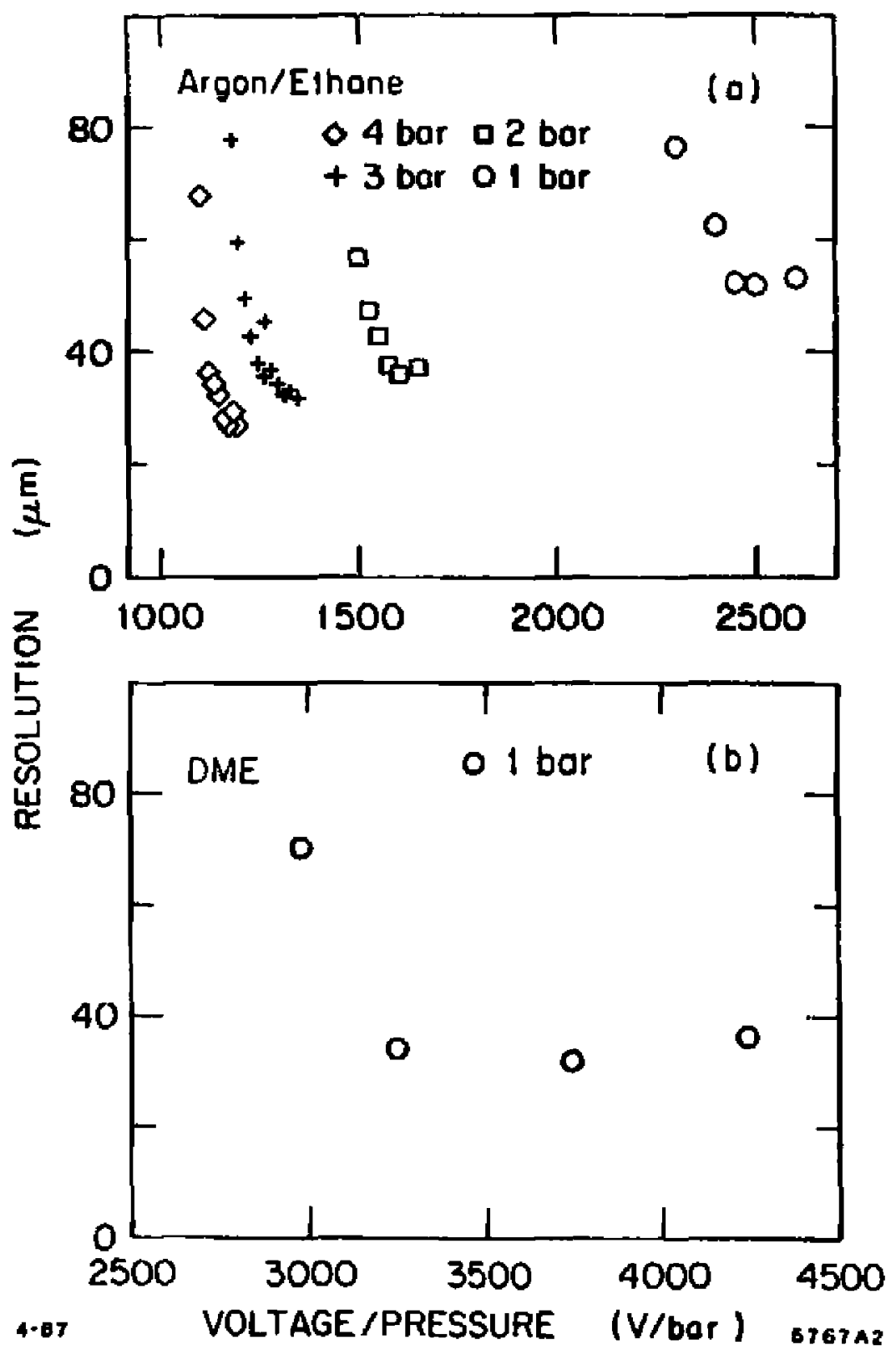

Fig. 2 

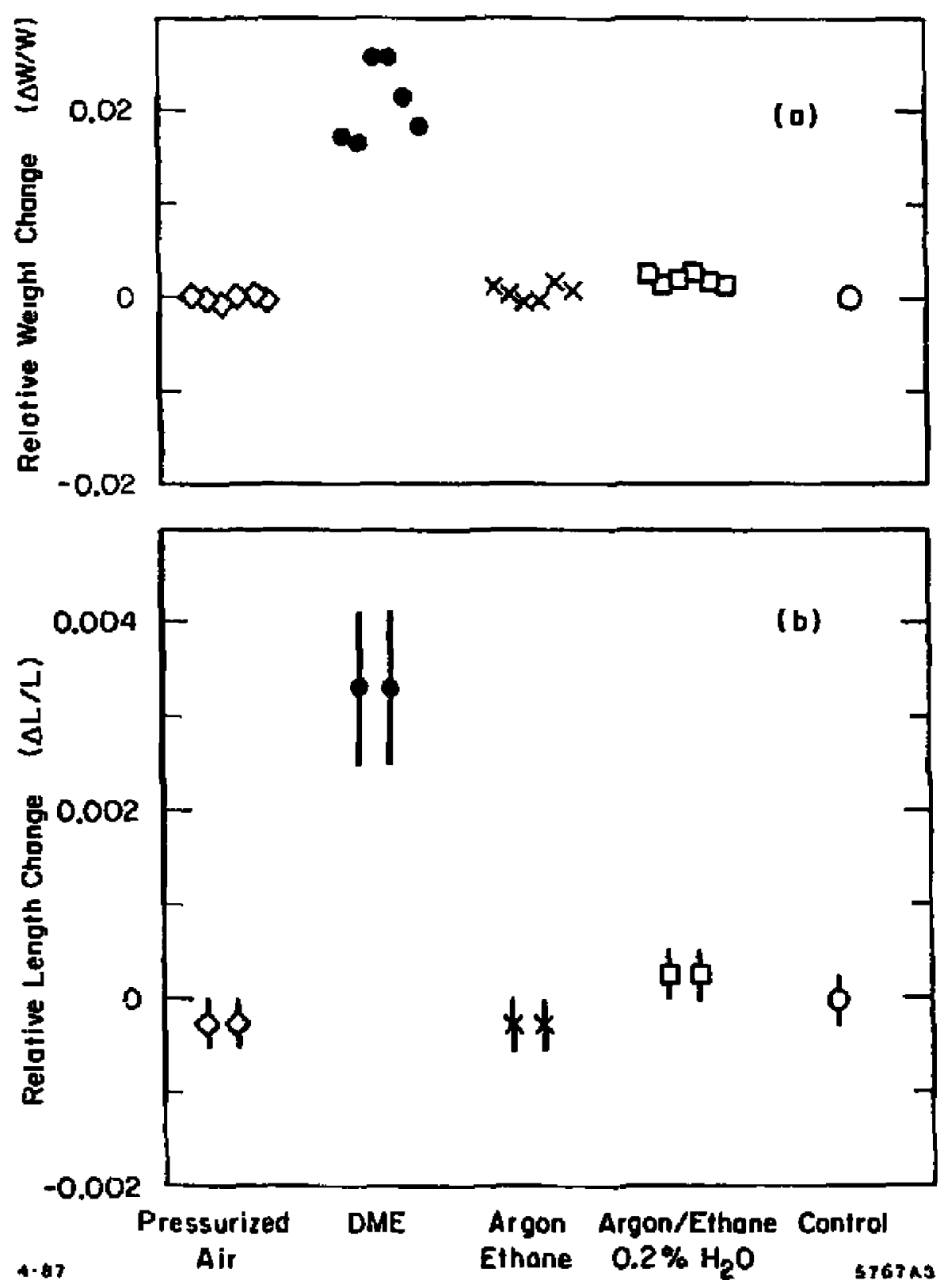

Fig. 3 